\title{
Effects of salinity build-up on the performance of an anaerobic membrane bioreactor regarding basic water quality parameters and removal of trace organic contaminants
}

\section{Revised Manuscript Submitted to Bioresource Technology}

May 2016

Xiaoye Song ${ }^{\mathrm{a}}$, James McDonald ${ }^{\mathrm{b}}$, William E. Price ${ }^{\mathrm{c}}$, Stuart J. Khan ${ }^{\mathrm{b}}$, Faisal I Hai ${ }^{\mathrm{a}}$, Hao H. Ngo ${ }^{\mathrm{d}}$, Wenshan Guo ${ }^{\mathrm{d}}$, Long D. Nghiem ${ }^{\mathrm{a}}$,

${ }^{a}$ Strategic Water Infrastructure Laboratory, School of Civil Mining and Environmental Engineering, University of Wollongong, Wollongong, NSW 2522, Australia

${ }^{b}$ School of Civil \& Environmental Engineering, University of New South Wales, NSW 2052,

\section{Australia}

${ }^{c}$ Strategic Water Infrastructure Laboratory, School of Chemistry, University of Wollongong, Wollongong, NSW 2522, Australia

${ }^{d}$ Centre for Technology in Water and Wastewater, School of Civil and Environmental Engineering, University of Technology Sydney, Sydney, NSW 2007, Australia

\footnotetext{
* Corresponding author: longn@uow.edu.au; Ph: +61 (2) 42214590.
} 


\section{ABSTRACT}

The effects of elevated inorganic salt concentration on anaerobic membrane bioreactor (AnMBR) treatment regarding basic biological performance and trace organic contaminant (TrOC) removal were investigated. A set of 33 TrOCs were selected to represent pharmaceuticals, steroid, pesticides in municipal wastewater. Results show potential adverse effects of increasing in the bioreactor salinity to $15 \mathrm{~g} / \mathrm{L}$ (as $\mathrm{NaCl}$ ) on the performance of AnMBR with the respect to the COD removal, biogas production, and the removal of most hydrophilic TrOCs. Furthermore, a decrease in biomass production was observed as salinity in the bioreactor increased. The removal of most hydrophobic TrOCs was high and was not significantly affected by salinity build-up in the bioreactor. The accumulation of a few persistent TrOCs in the sludge phase was observed, but such accumulation did not vary significantly as salinity in the bioreactor increased.

Key words: Salinity build-up; anaerobic membrane bioreactor (AnMBR); trace organic contaminants (TrOCs); wastewater treatment; biogas production.

\section{Introduction}

Water scarcity is a vexing challenge to the sustainable development of our society. This issue is further exacerbated by climate change, continuous population growth, industrialization and urbanization, and environmental pollution (Shannon et al., 2008). Moreover, an increasing number of trace organic contaminants (TrOCs) - including pharmaceuticals and personal products, endocrine disrupting compounds, and pesticides - are continuously released to the aquatic environmental through sewage effluent discharge and other human activities. This continuous release of TrOCs can compromise our limited water resources for drinking water supply (Schwarzenbach et al., 2006). As a result, much attention has been dedicated to the removal of TrOCs during wastewater treatment and to explore alternative water sources including wastewater to protect and increase water supply.

Membrane bioreactor (MBR) is a promising technology for wastewater treatment and water reuse (Judd et al., 2011; Hai et al., 2014; Jegatheesan et al., 2016). Recent studies have shown that MBR can have higher removal of some TrOCs in comparison to conventional activated sludge treatment (De Wever et al., 2007; Melvin et al., 2016). The observed enhanced TrOC removal can be attributed to the prolonged solid retention time (SRT) and high biomass 
concentration in the MBR systems (Hai et al., 2014). It is noteworthy that the removal of TrOCs by MBR investigated in most of previous studies was under an aerobic condition.

MBR can also be deployed in anaerobic configuration (i.e. AnMBR) (Liao et al., 2006; Lew et al., 2009; Skouteris et al., 2012). Compared to its aerobic counterpart, AnMBR is much more energy efficient due to the absence of aeration and enables the treatment of high strength wastewater with less sludge production (Skouteris et al., 2012). More importantly, biogas can be produced for beneficial use during AnMBR treatment. As a result, AnMBR has attracted much research interest over last decade and its industrial application is increasing remarkably (Lin et al., 2013). Most AnMBR studies have focused on the treatment of high strengh industrial wastewater (Saddoud et al., 2009; Stamatelatou et al., 2009; Dereli et al., 2012). Compared to industrial waswater, municipal wastewater has much lower strenght due to its dilution nature. Thus, anaerobic treatment may not suit to treat municipal wastewater given its long operating hydraulic retention time (HRT), energy requirement to maintain a mesophilic digestion temperature (approximately $35^{\circ} \mathrm{C}$ ), and large wastewater volume (Lew et al., 2009; Hai et al., 2014).

Recent interest to simultaneously recover energy and clean water during wastewater treatment has spurred new research to adapt AnMBRs for municipal wastewater treatment. One viable technique is to pre-concentrate the organic content (usually measured as chemical oxygen demand (COD)) of municipal wastewater to a range suitable for anaerobic treatment (Diamantis et al., 2013). This aim can be achieved by directly extracting clean water from municipal wastewater using forward osmosis or other high-retention membrane processes, resulting in a concentrated sewage solution (Xie et al., 2013; Zhang et al., 2014). However, the pre-concentration process prior to AnMBRs also entails the build-up of salinity in the concentrated municipal wastewater (Ansari et al., 2015). Moreover, since a high-retention membrane process can effectively retain TrOCs (Luo et al., 2014), their concentrations in pre-concentrated wastewater prior to AnMBR can be an order of magnitude higher than those in the initial wastewater solution. In addition, varying salinity of municipal wastewater also occurs in coastal regions due to seawater infiltration to sewers or when sewer systems receive discharges from industrial processes that involve saline water, such as seafood and cheese production (Yogalakshmi et al., 2010).

High salinity wastewater is a challenge to biological treatment (Lay et al., 2010). Elevated salinity can negatively affect the performance of aerobic MBR by inhibiting microbial 
activity and growth (Yogalakshmi et al., 2010). An increase in the osmotic stress can result in the dehydration and plasmolysis of microbial cells and thus their inactivity (Wood, 2015). Nevertheless, microbial acclimatization can lead to the succession of halotolerant and even halophibic bacteria, thereby gradually recovering the treatment performance (Luo et al., 2016). However, compared to aerobic MBR, little is known about the effects of high salinity on the performance of anaerobic MBR.

This study aims to investigate the effects of salinity build-up on the performance of AnMBR, particularly in terms of TrOC removal. Salinity build-up was stimulated by increasing the influent $\mathrm{NaCl}$ loading from 0 to $15 \mathrm{~g} / \mathrm{L}$. Basic performance of AnMBR was evaluated with respect to bulk organic removal, biomass growth, and biogas/methane production. Removal of TrOCs by AnMBR under the elevated salinity condition was related to their physicochemical properties, such as hydrophobicity and molecular structure. Results in this study would shed lights on the management of saline wastewater before AnMBR treatment.

\section{Materials and methods}

\subsection{Synthetic wastewater and trace organic contaminants}

A synthetic wastewater with approximately 6,000 mg/L COD (Table S1, Supplementary Data) was used to simulate high strength municipal wastewater and to maintain stable influent conditions. A concentrated stock solution was prepared every 5 days and kept at 4 ${ }^{\circ} \mathrm{C}$. The synthetic wastewater was prepared daily by diluting the concentrated stock solution with deionized water.

A set of 33 TrOCs, representing four key groups of emerging contaminants of significant concerns that present ubiquitously in municipal wastewater (i.e. pharmaceuticals, personal care products, industrial chemicals, and pesticides), were selected in this study. Key properties - including hydrophobicity and molecular structure - of these TrOCs are summarized in Table S2 of the Supplementary Data. These TrOCs can be classified as hydrophobic or hydrophilic depending on their effective octanol-water partition coefficient (denoted as $\log \mathrm{D})$. Compounds with $\log \mathrm{D}$ at solution $\mathrm{pH} 7$ higher than 3.2 are hydrophobic whereas compounds with $\log \mathrm{D}$ at solution $\mathrm{pH} 7$ lower than 3.2 are hydrophilic in a neutral condition (Tadkaew et al., 2011). A stock solution containing all $33 \mathrm{TrOCs}$ (10 mg/L of each) was prepared in pure methanol and stored at $-18{ }^{\circ} \mathrm{C}$ in the dark. The stock solution was used within one month. Regular measurements were conducted to confirm the constant concentration of the TrOC stock solution. 


\subsection{Experimental system and protocol}

A lab-scale AnMBR system was used in this study (Figure S1, Supplementary Data). This system comprised a $30 \mathrm{~L}$ stainless steel bioreactor, an external ceramic microfiltration (MF) membrane module (NGK, Japan), and several peristaltic and circulation pumps. The MF membrane had a pore size of $0.1 \mu \mathrm{m}$ and an effective area of $0.09 \mathrm{~m}^{2}$. A PID regulated heater (Neslab RTE7, Thermo Scientific, USA) equipped with a plastic heater exchange coil was used to maintain the bioreactor temperature at $35 \pm 1{ }^{\circ} \mathrm{C}$ over the entire experimental period. A peristaltic pump (Masterflex L/s, USA) controlled by water level controller was used to feed the bioreactor, which had a constant working volume of $20 \mathrm{~L}$. The digested sludge was circulated from the bioreactor to the external membrane module and then back to the bioreactor by a peristaltic pump with a circulation rate of $700 \mathrm{~mL} / \mathrm{min}$. At the same time, an industrial grade peristaltic hose pump (ProMinent, Australia) was used to mix the sludge by circulating it from the bottom to the top of the bioreactor. A Tedlar sampling bag was connected to the bioreactor for biogas collection. Both the bioreactor and pipes involved in this system were rapped with insulation foam to reduce heat loss. A detailed description of this system is also available elsewhere (Wijekoon et al., 2015).

Anaerobic sludge collected from the Wollongong Wastewater Treatment Plant was used to inoculate the bioreactor with feeding the synthetic wastewater described above for over 12 months. Once acclimatized in term of bulk organic removal (i.e. COD removal > 96\%), TrOCs were spiked to the synthetic wastewater on a daily basis to obtain a working concentration of $2 \mu \mathrm{g} / \mathrm{L}$ of each compound. The initial mixed liquor suspended solids (MLSS) concentration was adjusted to approximately $16 \mathrm{~g} / \mathrm{L}$. Salinity build-up in the bioreactor was induced by increasing the influent $\mathrm{NaCl}$ loading from 0 to $15 \mathrm{~g} / \mathrm{L}$ with an increase of $1 \mathrm{~g} / \mathrm{L}$ per day (Figure S2, Supplementary Data). To allow microbial acclimatization to the salinity stress, the influent salt salinity was maintained at 5,10 , and $15 \mathrm{~g} / \mathrm{L} \mathrm{NaCl}$ for two weeks. The MF membrane was operated in a cycle of 14 min suction and 1 min relaxation with a water flux of $1.8 \mathrm{~L} / \mathrm{m}^{2} \mathrm{~h}$, which resulted in an operating HRT of 5 days. The low water flux and relaxation time was provided to reduce membrane fouling. No sludge was wasted in this study, except for regular sludge sampling, which led to an operating SRT of 140 days. Sodium acetate was added to maintain the bioreactor $\mathrm{pH}$ of 7 . The MF membrane was chemically cleaned once a month by using a $20 \mathrm{mg} / \mathrm{L} \mathrm{NaOH}$ solution at $70 \pm 1{ }^{\circ} \mathrm{C}$ and then completely rinsed with deionized water. This cleaning procedure could completely recover 
the membrane permeability determined by the measured transmembrane pressure and water flux with deionized water as the feed.

\subsection{Analytical methods}

\subsubsection{Basic measurements}

MLSS and mixed liquor volatile suspended solids (MLVSS) concentrations were measured according to the Standard Methods for Examination of Water and Wastewater (APHA, 2005). Total organic carbon (TOC) and total nitrogen (TN) were analysed using a TOC/TN-VCSH analyser (Shimadzu, Japan). COD was measured using high range plus digestion vials (Hatch, USA) following the standard dichromate method. Mixed liquor electrical conductivity and $\mathrm{pH}$ were monitored by an Orion 4 Star Plus portable $\mathrm{pH} /$ conductivity meter (Thermo Scientific, USA). Biogas composition was revealed by a biogas meter (Biogas 5000, Geotech, UK).

\subsubsection{TrOC analysis}

Aqueous samples $(250 \mathrm{~mL}$ ) were taken twice (once per week) from the feed and permeate when the salinity was stabilized at $0,5,10$, and $15 \mathrm{~g} / \mathrm{L} \mathrm{NaCl}$ to analyse TrOC concentrations based on the method described previously by Tadkaew et al. (2011). Briefly, this method involved solid phase extraction (SPE), liquid chromatography, and quantitative measurement by tandem mass spectrometry with electrospray ionization. All samples were spiked with a surrogate solution that contained $50 \mathrm{ng}$ of each TrOC in an isotopically labelled version. The use of isotope dilution allows for SPE efficiency correction and complete elimination of any matrix effects (Trenholm et al., 2006). Oasis HLB cartridges (Waters, Millford, MA, USA) used for TrOC extraction were preconditioned using $5 \mathrm{~mL}$ methyl tert-butyl ether, $5 \mathrm{~mL}$ methanol, and $5 \mathrm{~mL}$ reagent water (two times). The cartridges were rinsed twice with $5 \mathrm{~mL}$ reagent water after SPE and then processed for nitrogen drying.

TrOCs were eluted from the loaded cartridges using $5 \mathrm{~mL}$ methanol, and then $5 \mathrm{~mL}$ mixture of methanol and methyl tert-butyl ether $(1: 9, \mathrm{v} / \mathrm{v})$. Resultant extracts were concentrated to $100 \mu \mathrm{L}$ by using nitrogen stream, which were subsequently diluted to $1 \mathrm{~mL}$ with methanol. The diluted extracts were processed to a high performance liquid chromatography (Agilent 1200 series, Palo Alto, CA, USA) with a Luna C18 (2) column (Phenomenex, Torrence CA, USA) for TrOC separation. Peaks of different TrOCs were identified and quantified by an isotope dilution method using a triple quadrupole mass spectrometer (API 4000, Applied Biosystems, Foster City, CA, USA) equipped with a turbo-V ion source that was employed in 
both positive and negative electro-spray modes. This measurement method had a limit of quantification of $20 \mathrm{ng} / \mathrm{L}$ for bisphenol A, $10 \mathrm{ng} / \mathrm{L}$ for caffeine, triclocarban and diuron, and 5 $\mathrm{ng} / \mathrm{L}$ for all other TrOCs.

The removal of TrOCs by the AnMBR system was determined from:

$R=\frac{C_{f}-C_{p}}{C_{f}} \times 100 \%$

where $C_{f}$ and $C_{p}$ were the measured TrOC concentrations in the feed and permeate, respectively.

TrOCs resided in the sludge were measured twice (once per week) when the salinity was stabilized at $0,5,10$, and $15 \mathrm{~g} / \mathrm{L} \mathrm{NaCl}$ based on a method previously reported by Wijekoon et al. (2013). In brief, the mixed liquor was centrifuged at $3750 \mathrm{~g}$ for 20 mins to obtain sludge pellet, which was then freeze-dried using a Freeze Dryer (Alpha 1-2 LDplus, Christ GmbH, Germany). The dried sludge was completely ground and $0.5 \mathrm{~g}$ sludge powder was mixed with $5 \mathrm{~mL}$ methanol in a glass valve using a vortex mixer (VM1, Ratek, Australia). The mixture was ultrasonicated at $40{ }^{\circ} \mathrm{C}$ for $10 \mathrm{~min}$ and then centrifuged ( $3270 \mathrm{~g}$ for $10 \mathrm{~min}$ ). The supernatant was collected while the remaining pellet was mixed with $5 \mathrm{~mL}$ dichloromethane and methanol mixture $(1: 1, v / v)$, and then processed for ultrasonication and centrifugation. Supernatant collected from these two steps was purged with nitrogen gas to removed residual methanol and dichloromethane, and then diluted to $250 \mathrm{~mL}$ with Milli-Q water for TrOC analysis using the method described above for aqueous samples.

\section{Results and discussion}

\subsection{Basic performance}

\subsubsection{Removal of bulk organic matter}

Small and transient decrease in the TOC removal by AnMBR was observed as the the bioreactor salinity increased (Figure 1). At baseline condition (i.e. negligible salinity in the bioreactor), the TOC removal was constant at approximately $98 \%$. When salinity in the bioreactor increased to $5 \mathrm{~g} / \mathrm{L} \mathrm{NaCl}$, the TOC removal decreased to $82 \%$. This observed decrease was temporary and could be attributed to the negative effect of the elevated bioreactor salinity on the digester activity. It has been reported that salinity increase could resulted in cell plasmolysis and the loss of metabolic activity either in anaerobic or aerobic conditions (Lay et al., 2010). Similar to that in aerobic MBR systems, microbial 
acclimatization to the saline condition recovered the TOC removal to the initial level (i.e. $98 \%$ removal). No significant impact on the TOC removal was observed even when the bioreactor salinity continuously increased up to $15 \mathrm{~g} / \mathrm{L} \mathrm{NaCl}$.

\section{[FIGURE 1]}

The elevated bioreactor salinity reduced the COD removal by AnMBR, particularly at the salinity above $10 \mathrm{~g} / \mathrm{L} \mathrm{NaCl}$ (Figure 1). Similar to the TOC removal, at baseline condition (i.e. negligible salinity in the bioreactor), the COD removal was more than $98 \%$. There was no notable effect on the COD removal as the bioreactor salinity increased to less than $10 \mathrm{~g} / \mathrm{L}$ $\mathrm{NaCl}$. This observation is in good agreement with that reported by $\mathrm{Gu}$ et al. (2015) who reported that the biological COD removal was relatively stable although the mixed liquor electrical conductivity increased up to $20 \mathrm{mS} / \mathrm{cm}$ (corresponding to approximately $10 \mathrm{~g} / \mathrm{L}$ $\mathrm{NaCl}$ ) during the operation of an anaerobic osmotic membrane bioreactor (AnOMBR) at a mesophilic condition. However, a dramatic decrease in the COD removal (to approximately $80 \%$ ) was observed when the bioreactor salinity rose beyond $10 \mathrm{~g} / \mathrm{L} \mathrm{NaCl}$ (Figure 1). Previous studies have also reported the negative impact of such high salinity on the COD removal by anaerobic processes, such as upflow anaerobic sludge blanket reactor (Aslan et al., 2016) and sequential anaerobic and aerobic treatment (Shi et al., 2014). Although there was some evidence of treatment recovery possibly due to microbial acclimatization, the downward trend of COD removal under highly saline conditions (i.e. salinity $>10 \mathrm{~g} / \mathrm{L} \mathrm{NaCl}$ ) persisted. These results suggest that salinity build-up in the bioreactor beyond $10 \mathrm{~g} / \mathrm{L} \mathrm{NaCl}$ could adversely affect the AnMBR performance.

Results in Figure 1 show that AnMBR exhibited different variations in the removal of TOC and COD in response to the salinity increase. This difference was possibly due to the susceptibility of microbial communities (that were responsible for the biodegradation of unoxidisable organic matter) to the low saline stress. Nevertheless, further studies are necessary to track changes in microbial community structure in response to the elevated bioreactor salinity during AnMBR treatment.

Without a nitrification step, TN removal by anaerobic digesters is limited and mainly relies on microbial assimilation. In this study, a significant decrease in the TN removal was observed at the beginning of AnMBR operation without $\mathrm{NaCl}$ addition (Figure 1). The reason for such decrease is not clear, but was probably due to the adverse impacts of methanol (used 
to dissolve TrOCs) on nitrogen assimilation by digesters. As the bioreactor salinity gradually increased up to $15 \mathrm{~g} / \mathrm{L} \mathrm{NaCl}$, the TN removal only fluctuated in the range of $10-20 \%$.

\subsubsection{Biogas production}

Biogas production was relatively stable $\left(0.4-0.6 \mathrm{~L} / \mathrm{g} \mathrm{COD}_{\text {loaded }}\right)$ in response to an increase in bioreactor salinity during AnMBR operation (Figure 2). Only a small decrease was observed as the salinity increased to above $10 \mathrm{~g} / \mathrm{L} \mathrm{NaCl}$. This observation is consistent with the decreased COD removal at such high salinity (Figure 1). Nevertheless, the methane composition in the produced biogas was stable in the range of $58-65 \%$ over the entire experimental period (Figure 2), which is similar to that reported in a recent study (Wijekoon et al., 2015), where the AnMBR system was operated for over 140 days under the same conditions but without loading $\mathrm{NaCl}$ in the feed. These results indicate that salinity build-up in bioreactor (up to $15 \mathrm{~g} / \mathrm{L} \mathrm{NaCl}$ ) may not significantly affect the bioactivity of methanogensis. Gu et al. (2015) also observed a stable methane yield regardless of salinity build-up in the bioreactor during AnOMBR operation.

\section{[FIGURE 2]}

\subsubsection{Biomass concentration}

Salinity build-up in the bioreactor reduced the active digesters during AnMBR operation (Figure 3). At the baseline condition (i.e. negligible salinity in the bioreactor), both MLSS and MLVSS concentration were relatively stable with the MLVSS/MLSS ratio at approximately 0.7 , suggesting that most digesters in the mixed liquor were active. As the bioreactor salinity was enhanced to higher than $10 \mathrm{~g} / \mathrm{L} \mathrm{NaCl}$, an increase in the MLSS concentration (from 16 to $22 \mathrm{~g} / \mathrm{L}$ ) was observed while the MLVSS concentration decreased significantly. This observation could be attributed to the negative effects on the bioactivity of anaerobic digesters. Similar results have also been reported in aerobic MBR systems, in which the elevated salinity resulted in dead cells and increased the secretion of extracellular polymeric substances in the bioreactor, thus increasing the MLSS but reducing the MLVSS concentrations (Tadkaew et al., 2013; Luo et al., 2015).

\section{[FIGURE 3]}

\subsection{Removal of trace organic contaminants}

A qualitative framework has been previously developed and evaluated by Wijekoon et al. (2015) to predict the removal of various TrOCs by AnMBR based on their physicochemical 
properties, mainly including hydrophobicity and molecular structure. A similar predictive framework has also been widely applied to evaluate TrOC removal by aerobic MBR (Tadkaew et al., 2011). As noted in Section 2.1, the 33 TrOCs selected in current study could be classified as hydrophobic (i.e. $\log \mathrm{D}>3.2$ ) and hydrophilic (i.e. $\log \mathrm{D}<3.2$ ). Therefore, the removal of TrOCs by AnMBR under the elevated bioreactor salinity was related to their physicochemical properties based on these predictive frameworks (Figure 4).

\section{[FIGURE 4]}

\subsubsection{Removal of hydrophobic trace organic contaminants}

The removal of hydrophobic TrOCs (with $\log \mathrm{D}>3.2$ at $\mathrm{pH} 7$ ) by AnMBR was higher than $80 \%$ with a few exceptions (including phenylphenol, bisphenol A, and triclosan) (Figure 4a). More importantly, despite the decreasing active digester concentration (Figure 3), the removal of most of these hydrophobic TrOCs was not significantly affected by the elevated bioreactor salinity. The high removal of these compounds could be attributed to their effective adsorption onto sludge, which could increase their biodegradation (Monsalvo et al., 2014; Wijekoon et al., 2015).

Relatively low removal rates were observed for three hydrophobic compounds, including phenylphenol, bisphenol A, and triclosan (Figure 4a). The removal of phenylphenol was only $60 \%$ at baseline salinity (i.e. no $\mathrm{NaCl}$ addition) and decreased at the bioreactor salinity higher than $10 \mathrm{~g} / \mathrm{L} \mathrm{NaCl}$. Such low removal could be due to the relatively low hydrophobicity of phenylphenol $(\log \mathrm{D}=3.3$ at $\mathrm{pH} 7)$. By contrast, the removal of clozapine (which had a lower hydrophobicity than phenylphenol) was in the range of $80-98 \%$ although a small decrease was observed with salinity increase. The observed difference in the removal of these two compounds likely results from their different biodegradability, which determines the mineralization of TrOCs in biological treatment. Bisphenol A was poorly removed and its removal rate reduced from 40 to $20 \%$ as the bioreactor salinity climbed from negligible to 15 $\mathrm{g} / \mathrm{L} \mathrm{NaCl}$. The low removal of bisphenol A is consistent with that reported by Monsalvo et al. (2014) and could be ascribed to its low adsorption onto digesters although it had a relative high hydrophobicity $(\log \mathrm{D}=3.6$ at $\mathrm{pH} 7)$. On the other hand, the removal of triclosan increased from 40 to $60 \%$ with salinity increase up to $15 \mathrm{~g} / \mathrm{L} \mathrm{NaCl}$. This result was possibly due to the enhanced adsorption of triclosan on the digesters as salinity increased (Figure 5a). 


\subsubsection{Removal of hydrophilic trace organic contaminants}

The removal of hydrophilic TrOCs ( $\log \mathrm{D}<3.2$ at $\mathrm{pH} 7)$ varied significantly during AnMBR operation at baseline salinity (i.e. negligible salinity in the bioreactor) (Figure 4b). This result is in good agreement with that reported by Wijekoon et al. (2015) who attributed such varying removal to the different biodegradability of these hydrophilic TrOCs, which was further determined by their molecular structures. Similar results have also been reported in anaerobic MBR treatment (Tadkaew et al., 2011). In this study, several hydrophilic TrOCs, including trimethoprim, carazolol, hydroxyzine, amitriptyline, and linuron, were highly removed (with removal rates above $80 \%$ ). Such effective removal was due to their high biodegradability with presence of electron donating functional groups, such as hydroxyl and amine, in the molecular structure (Table S2, Supplementary Data). On the other hand, relative low removal rates were observed for other hydrophilic TrOCs due to their resistance of anaerobic biodegradation with the presence of electro withdrawing groups (e.g. chlorine and amide) in their molecular structures (Wijekoon et al., 2015).

The elevated bioreactor salinity significantly reduced the removal of most hydrophilic TrOCs (Figure 4b). Similar results have also been reported by Luo et al. (2015) although an aerobic MBR with activated sludge was used in their study. These results suggest that the inhibition of sludge metabolic activity caused by salinity build-up in the bioreactor could adversely affect the removal of hydrophilic TrOCs either under aerobic or anaerobic conditions. Nevertheless, a decrease but subsequent increase in the removal rate was observed for trimethoprim. This observation could be attributed to the acclimatization of microbial species that were responsible for trimethoprim biodegradation to the saline stress.

Of the 24 hydrophilic TrOCs investigated in this study, the removal of three compounds (i.e. verapamil, hydroxyzine, and simazine) increased with salinity build-up in the bioreactor. The enhanced removal of verapamil and hydroxyzine could be attributed to an increase in their adsorption onto sludge as the bioreactor salinity elevated (Figure 5b). By contrast, the adsorption of simazine was constantly negligible over the entire experimental period. Therefore, the increased overall removal of simazine by AnMBR was possibly due to the development of salt-tolerant bacteria that specifically target the compound. Nevertheless, future studies are needed to relate such removal behaviours to the variation of microbial community structure in response to the elevated bioreactor salinity. 


\subsubsection{Adsorption of trace organic contaminants onto sludge}

Hydrophobicity and biodegradability of TrOCs are important factors determining their residuals in the sludge. In this study, the accumulation of hydrophobic TrOCs was relatively low in the digesters, although they were supposed to highly adsorb onto sludge (Figure 5a). This observation could be attributed to the readily biodegradable nature of these compounds. A fluctuated but discernable increase in the residual content was observed for several compounds in response to the elevated bioreactor salinity. These compounds included clozapine, bisphenol A, triclosan, triclocarban, and nonylphenol. Of the five compounds, the increased accumulation in the sludge was more significant for clozapine and bisphenol A, possibly due to their disrupted biodegradation at high salinity (Figure 4a). On the other hand, the digesters might be more hydrophobic at high salinity condition, thereby enhancing the adsorption of triclosan, triclocarban, and nonylphenol, which were highly hydrophobic.

\section{[FIGURE 5]}

No significant accumulation in the sludge was observed for hydrophilic TrOCs, with a few exceptions, including carazolol, verapamil, hydroxyzine, and amitriptyline (Figure 5b). This result is consistent with that reported by Stevens-Garmon et al. (2011) and Wijekoon Wijekoon et al. (2015) who attributed the notable accumulation of these four compounds onto anaerobic digesters to their moderate hydrophobicity, modest biological persistence, and negative charge. Moreover, the elevated bioreactor salinity could decrease their biodegradation (indicated by the decreased removal by AnMBR, Figure 4b) and thus increased their residue in the digesters (Figure 5b).

\section{Conclusion}

Results reported here show that elevated bioreactor salinity negatively affected the performance of AnMBR for wastewater treatment. Both bulk organic removal (indicated by TOC and COD) and biogas/methane production decreased as the bioreactor salinity increased to above $10 \mathrm{~g} / \mathrm{L} \mathrm{NaCl}$. Of the 33 TrOCs investigated here, the high salinity reduced the removal of most hydrophilic compounds, but insignificantly affected the removal of hydrophobic ones by AnMBR. Moreover, slight impacts on TrOC residues in the sludge were observed with salinity increase. These results suggest that pre-treatment of saline wastewater may be required to ensure the effectiveness and sustainability of AnMBR treatment. 


\section{Acknowledgements}

Xiaoye Song would like to thank the Chinese Scholarship Council and the University of Wollongong for PhD scholarship support.

\section{References}

[1] Ansari, A.J., Hai, F.I., Guo, W., Ngo, H.H., Price, W.E., Nghiem, L.D. 2015.

Selection of forward osmosis draw solutes for subsequent integration with anaerobic treatment to facilitate resource recovery from wastewater. Bioresour. Technol., 191, 30-36.

[2] APHA. 2005. Standard Methods for the Examination of Water and Wastewater. Washington, D. C. : American Public Health Association, 2005.

[3] Aslan, S., Şekerdağ, N. 2016. Salt inhibition on anaerobic treatment of high salinity wastewater by upflow anaerobic sludge blanket (UASB) reactor. Desalin. Water Treat., 57(28), 12998-13004.

[4] De Wever, H., Weiss, S., Reemtsma, T., Vereecken, J., Müller, J., Knepper, T., Rörden, O., Gonzalez, S., Barcelo, D., Dolores Hernando, M. 2007. Comparison of sulfonated and other micropollutants removal in membrane bioreactor and conventional wastewater treatment. Water Res., 41, 935-945.

[5] Dereli, R.K., Ersahin, M.E., Ozgun, H., Ozturk, I., Jeison, D., van der Zee, F., van Lier, J.B. 2012. Potentials of anaerobic membrane bioreactors to overcome treatment limitations induced by industrial wastewaters. Bioresour. Technol., 122, 160-170.

[6] Diamantis, V., Verstraete, W., Eftaxias, A., Bundervoet, B., Vlaeminck, S.E., Melidis, P., Aivasidis, A. 2013. Sewage pre-concentration for maximum recovery and reuse at decentralized level. Water Sci. Technol., 67(6), 1188-1193.

[7] Gu, Y., Chen, L., Ng, J.-W., Lee, C., Chang, V.W.C., Tang, C.Y. 2015. Development of anaerobic osmotic membrane bioreactor for low-strength wastewater treatment at mesophilic condition. J. Membr. Sci., 490, 197-208.

[8] Hai, F.I., Yamamoto, K., Lee, C.H. 2014. Membrane biological reactors: theory, modeling, design, management and applications to wastewater reuse. IWA Publishing, London.

[9] Jegatheesan, V., Pramanik, B.K., Chen, J., Navaratna, D., Chang, C.-Y., Shu, L. 2016. Treatment of textile wastewater with membrane bioreactor: A critical review. Bioresour. Technol., 204, 202-212. 
[10] Judd, S., Judd, C. 2011. The MBR book : principles and applications of membrane bioreactors for water and wastewater treatment. IWA Publishing, London.

[11] Lay, W.C., Liu, Y., Fane, A.G. 2010. Impacts of salinity on the performance of high retention membrane bioreactors for water reclamation: A review. Water Res., 44(1), 21-40.

[12] Lew, B., Tarre S., Beliavski M., Dosoretz C., M., G. 2009. Anaerobic membrane bioreactor (AnMBR) for domestic wastewater treatment. Desalination, 243(1), 251257.

[13] Liao, B.Q., Kraemer, J.T., Bagley, D.M. 2006. Anaerobic membrane bioreactors: applications and research directions. Environ. Sci. Technol., 36(6), 489-530.

[14] Lin, H., Peng, W., Zhang, M., Chen, J., Hong, H., Zhang, Y. 2013. A review on anaerobic membrane bioreactors: Applications, membrane fouling and future perspectives. Desalination, 314, 169-188.

[15] Luo, W., Hai, F.I., Kang, J., Price, W.E., Guo, W., Ngo, H.H., Yamamoto, K., Nghiem, L.D. 2015. Effects of salinity build-up on biomass characteristics and trace organic chemical removal: implications on the development of high retention membrane bioreactors. Bioresour. Technol., 177, 274-81.

[16] Luo, W., Hai, F.I., Price, W.E., Guo, W., Ngo, H.H., Yamamoto, K., Nghiem, L.D. 2014. High retention membrane bioreactors: challenges and opportunities. Bioresour. Technol., 167, 539-46.

[17] Luo, W., Phan, H.V., Hai, F.I., Price, W.E., Guo, W., Ngo, H.H., Yamamoto, K., Nghiem, L.D. 2016. Effects of salinity build-up on the performance and bacterial community structure of a membrane bioreactor. Bioresour. Technol., 200, 305-10.

[18] Melvin, S.D., Leusch, F.D.L. 2016. Review article: Removal of trace organic contaminants from domestic wastewater: A meta-analysis comparison of sewage treatment technologies. Environment International, 92-93, 183-188.

[19] Monsalvo, V.M., McDonald, J.A., Khan, S.J., Le-Clech, P. 2014. Removal of trace organics by anaerobic membrane bioreactors. Water Res., 49, 103-112.

[20] Saddoud, A., Abdelkafi, S., Sayadi, S. 2009. Effects of domestic wastewater toxicity on anaerobic membrane-bioreactor (MBR) performances. Environ. Technol., 30(13), 1361-1369.

[21] Schwarzenbach, R.P., Escher, B.I., Fenner, K., Hofstetter, T.B., Johnson, C.A., von Gunten, U., Wehrli, B. 2006. The Challenge of Micropollutants in Aquatic Systems. Science, 313, 1072-1077. 
[22] Shannon, M.A., Bohn, P.W., Elimelech, M., Georgiadis, J.G., Mariñas, B.J., Mayes, A.M. 2008. Science and technology for water purification in the coming decades. Nature, 452(7185), 301-310.

[23] Shi, X., Lefebvre, O., Ng, K.K., Ng, H.Y. 2014. Sequential anaerobic-aerobic treatment of pharmaceutical wastewater with high salinity. Bioresour. Technol., 153, 79-86.

[24] Skouteris, G., Hermosilla, D., López, P., Negro, C., Blanco, Á. 2012. Anaerobic membrane bioreactors for wastewater treatment: A review. Chem. Eng. J., 198-199, 138-148.

[25] Stamatelatou, K., Kopsahelis, A., Blika, P.S., Paraskeva, C.A., Lyberatos, G. 2009. Anaerobic digestion of olive mill wastewater in a periodic anaerobic baffled reactor (PABR) followed by further effluent purification via membrane separation technologies. J. Chem. Technol. Biot., 84(6), 909-917.

[26] Stevens-Garmon, J., Drewes, J.E., Khan, S.J., McDonald, J.A., Dickenson, E.R.V. 2011. Sorption of emerging trace organic compounds onto wastewater sludge solids. Water Res., 45, 3417-3426.

[27] Tadkaew, N., Hai, F.I., McDonald, J.A., Khan, S.J., Nghiem, L.D. 2011. Removal of trace organics by MBR treatment: The role of molecular properties. Water Res., 45(8), 2439-2451.

[28] Tadkaew, N., McDonald, J., Khan, S.J., Nghiem, L.D. 2013. Effects of salinity on the removal of trace organic contaminants by membrane bioreactor treatment for water reuse. Desalin. Water Treat.(25-27), 5164-5171.

[29] Trenholm, R.A., Vanderford, B.J., Holady, J.C., Rexing, D.J., Snyder, S.A. 2006. Broad range analysis of endocrine disruptors and pharmaceuticals using gas chromatography and liquid chromatography tandem mass spectrometry.

Chemosphere, 65(11), 1990-1998.

[30] Wijekoon, K.C., Hai, F.I., Kang, J., Price, W.E., Guo, W., Ngo, H.H., Nghiem, L.D. 2013. The fate of pharmaceuticals, steroid hormones, phytoestrogens, UV-filters and pesticides during MBR treatment. Bioresour. Technol., 144, 247-254.

[31] Wijekoon, K.C., McDonald, J.A., Khan, S.J., Hai, F.I., Price, W.E., Nghiem, L.D. 2015. Development of a predictive framework to assess the removal of trace organic chemicals by anaerobic membrane bioreactor. Bioresour. Technol., 189, 391-8.

[32] Wood, J.M. 2015. Bacterial responses to osmotic challenges. J. Gen. Physiol., 145(5), 381-388. 
[33] Xie, M., Nghiem, L.D., Price, W.E., Elimelech, M. 2013. A forward osmosismembrane distillation hybrid process for direct sewer mining: system performance and limitations. Environ. Sci. Technol., 47(23), 13486-93.

[34] Yogalakshmi, K.N., Joseph, K. 2010. Effect of transient sodium chloride shock loads on the performance of submerged membrane bioreactor. Bioresour. Technol., 101, 7054-7061.

[35] Zhang, X., Ning, Z., Wang, D.K., Diniz da Costa, J.C. 2014. Processing municipal wastewaters by forward osmosis using CTA membrane. J. Membr. Sci., 468, 269-275. 


\section{LIST OF FIGURES}

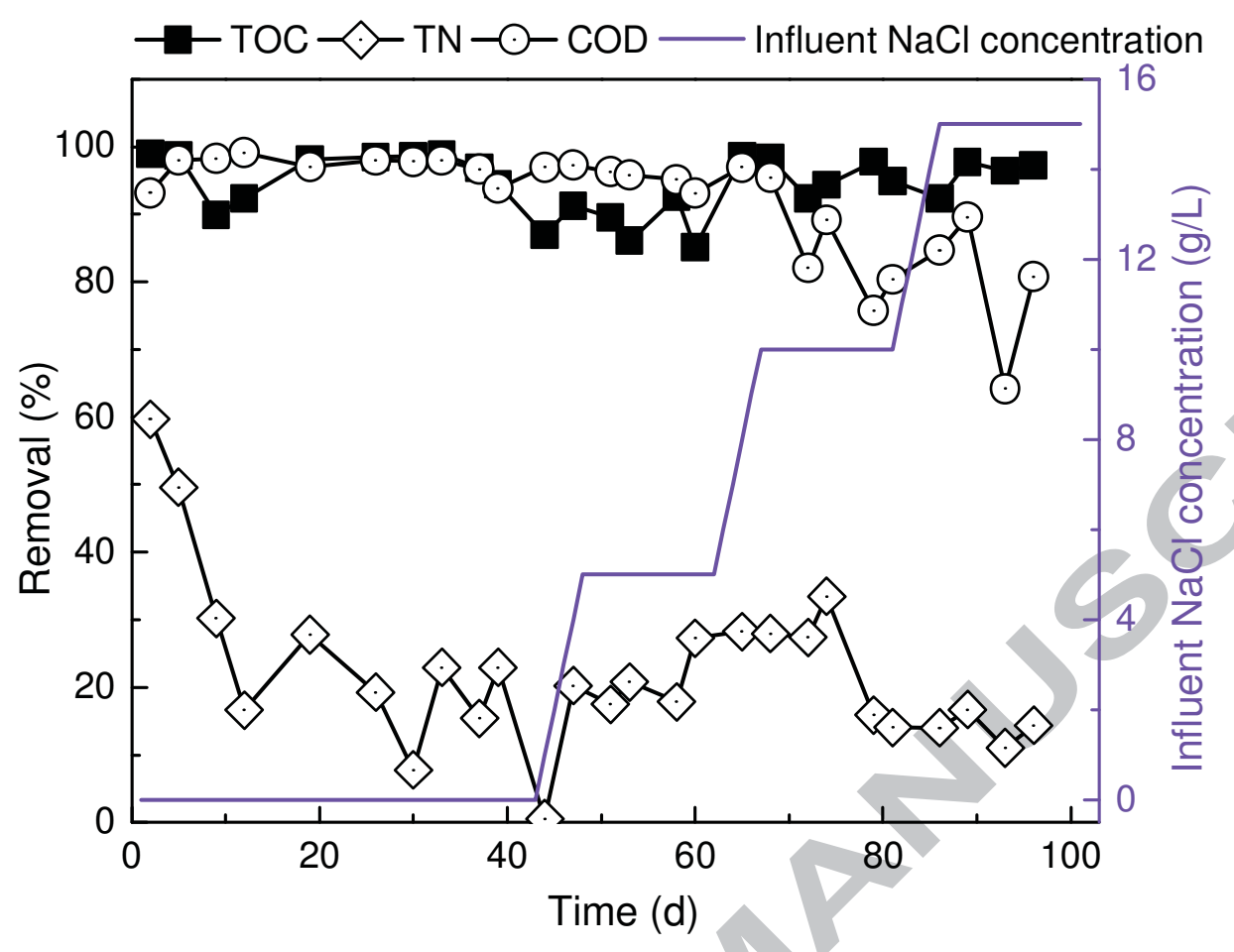

Figure 1: Effects of salinity build-up in the bioreactor on the removal of bulk organic matter (i.e. TOC, TN, and COD) by AnMBR. Salinity build-up in the bioreactor was simulated by increasing the feed $\mathrm{NaCl}$ concentration from 0 to $15 \mathrm{~g} / \mathrm{L}$. Experimental conditions: initial MLSS $=16 \mathrm{~g} / \mathrm{L} ; \mathrm{HRT}=5 \mathrm{~d}$; mixed liquor $\mathrm{pH}=7 \pm 0.1$ (adjusted by sodium acetate); temperature $=35 \pm 1^{\circ} \mathrm{C}$. 


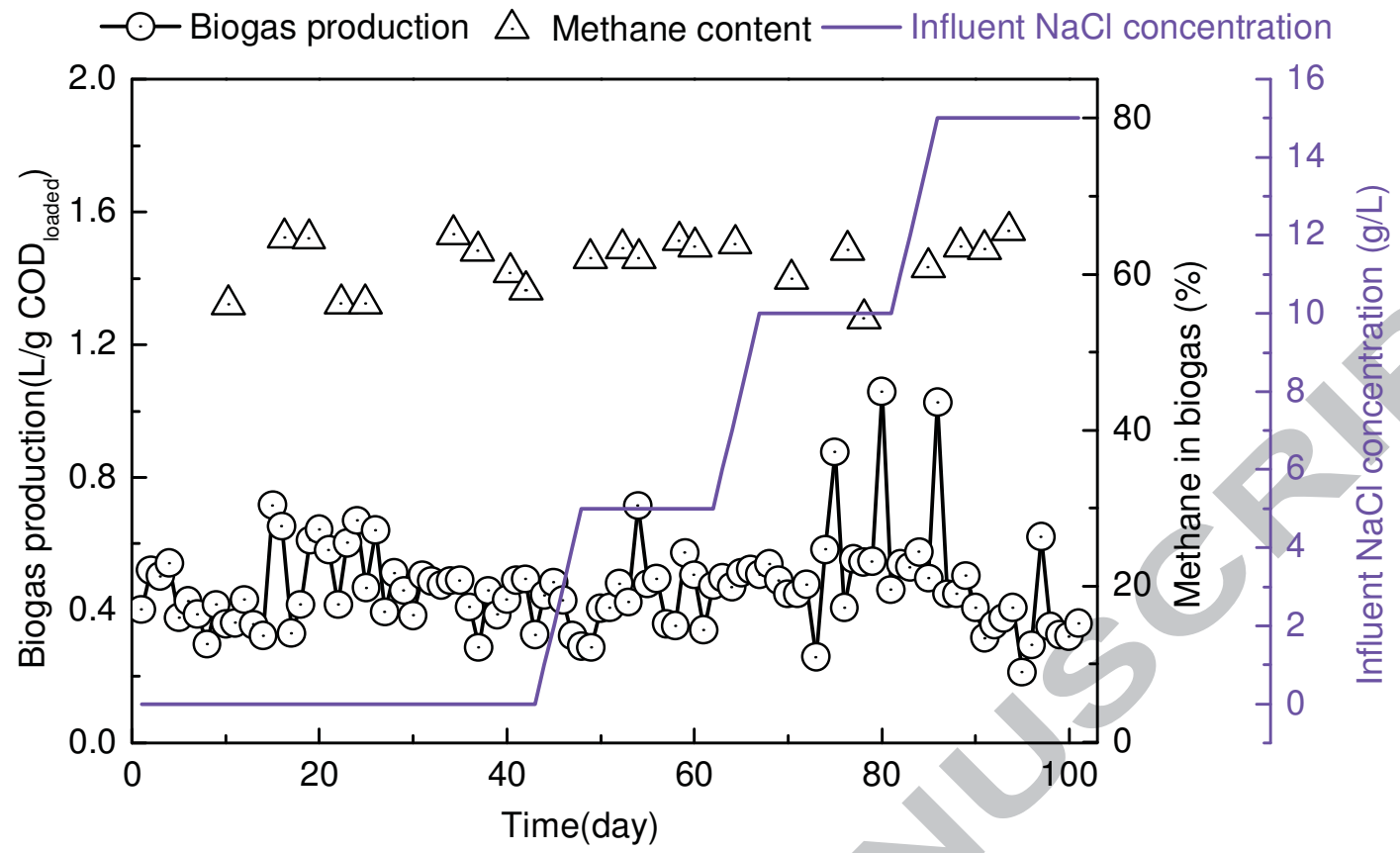

Figure 2: Effect of salinity build-up in the bioreactor on biogas production and its methane content during AnMBR operation. Salinity build-up in the bioreactor was simulated by increasing the feed $\mathrm{NaCl}$ concentration from 0 to $15 \mathrm{~g} / \mathrm{L}$. Experimental conditions are as described in the caption of Figure 1. 


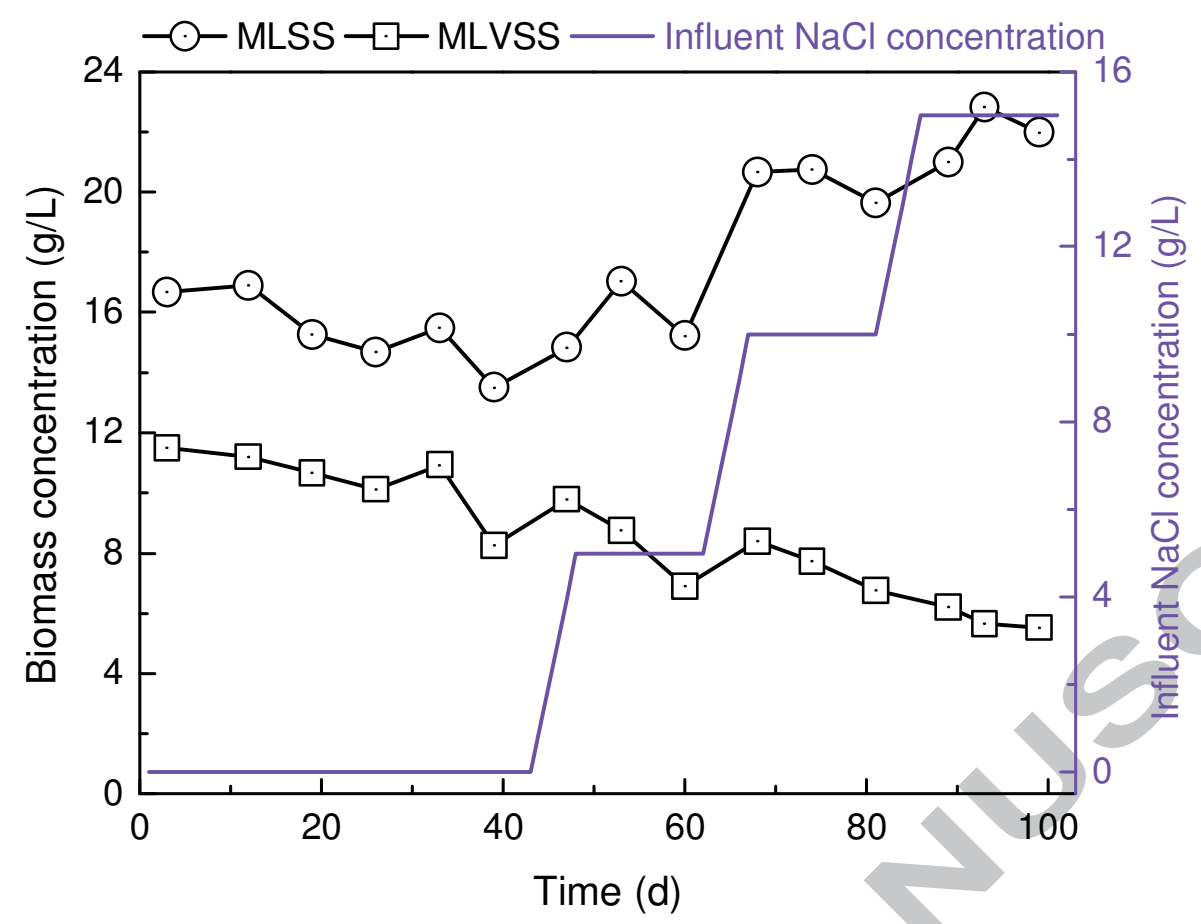

Figure 3: Effect of salinity build-up in the bioreactor on biomass concentration during AnMBR operation. Salinity build-up in the bioreactor was simulated by increasing the feed $\mathrm{NaCl}$ concentration from 0 to $15 \mathrm{~g} / \mathrm{L}$. Experimental conditions are as described in the caption of Figure 1. 
(a)

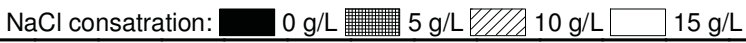
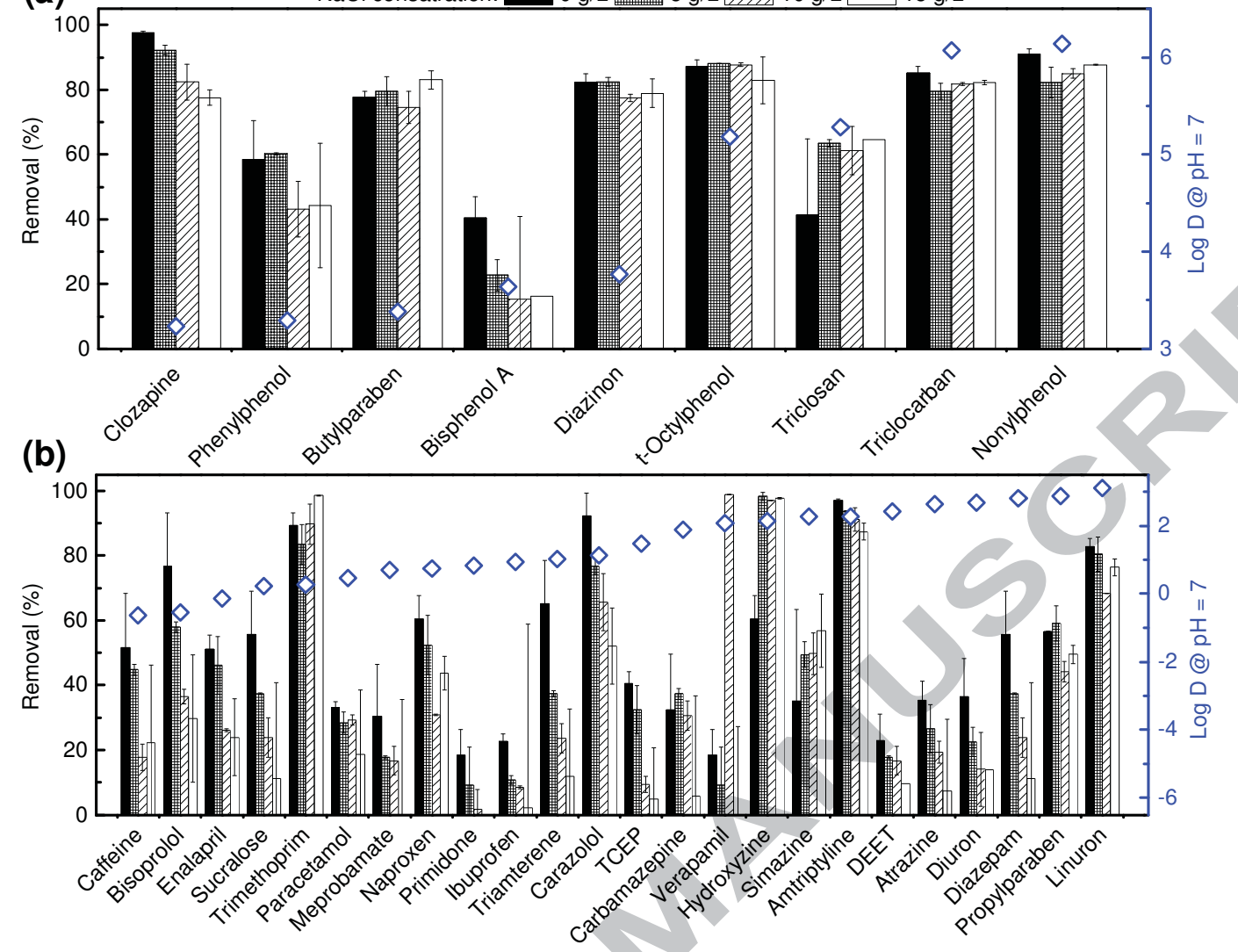

Figure 4: Effects of salinity build-up in the bioreactor on the removal of TrOCs by AnMBR treatment. The 33 TrOCs investigated could be grouped into hydrophobic ( $\log \mathrm{D}>3.2$ at $\mathrm{pH}$ 7) and hydrophilic ( $\log \mathrm{D}<3.2$ at $\mathrm{pH} 7)$. Salinity build-up in the bioreactor was simulated by gradually increasing the feed $\mathrm{NaCl}$ concentration from 0 to $15 \mathrm{~g} / \mathrm{L}$. To allow microbial acclimatization to the salinity stress, the influent salt salinity was maintained at 5,10 , and 15 $\mathrm{g} / \mathrm{L} \mathrm{NaCl}$ for two weeks. Error bars represent the standard deviation of two measurements (once per week) at each salinity condition. 

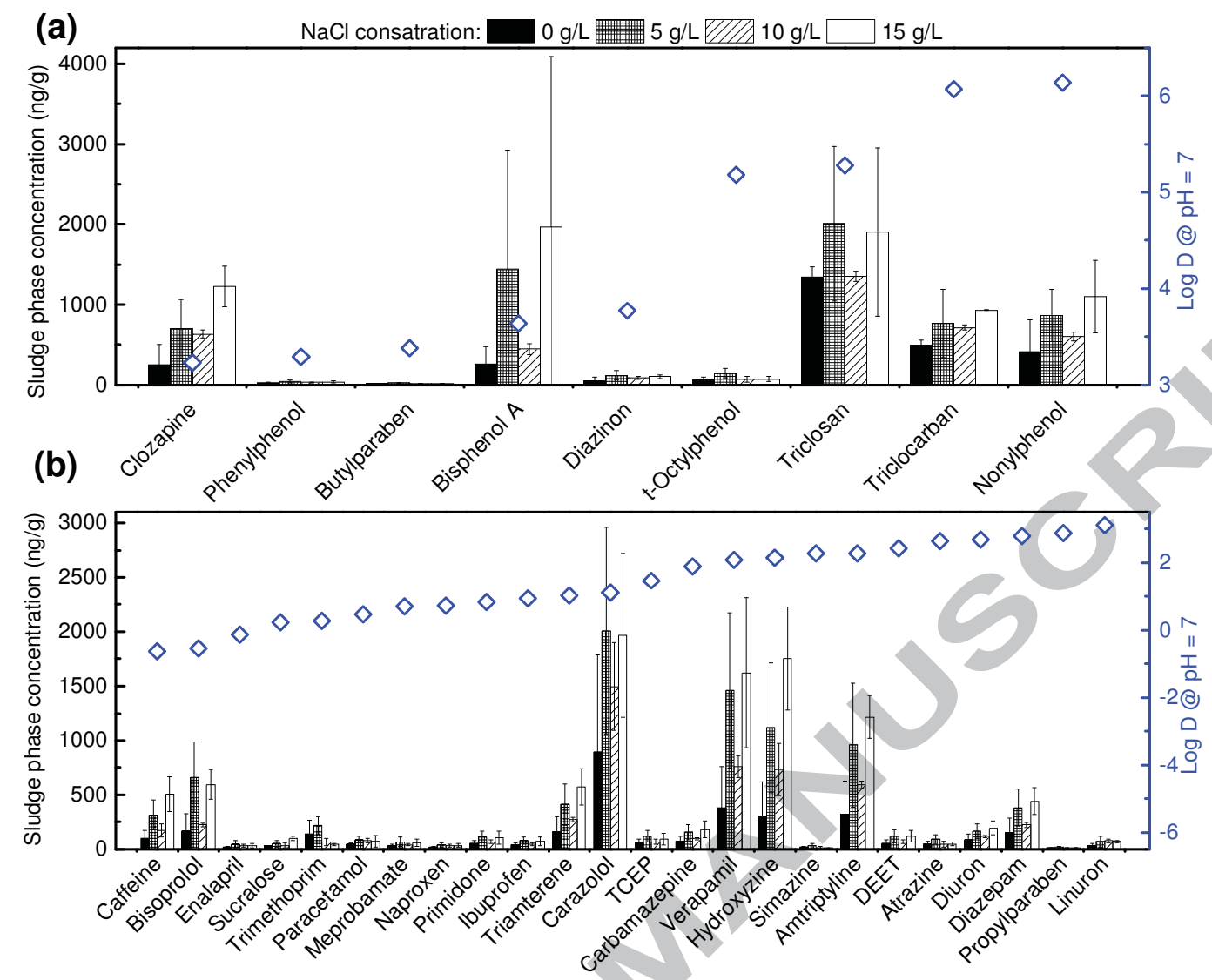

Figure 5: Effect of salinity build-up in the bioreactor on TrOC accumulation in the sludge during AnMBR operation. Salinity build-up in the bioreactor was simulated by gradually increasing the feed $\mathrm{NaCl}$ concentration from 0 to $15 \mathrm{~g} / \mathrm{L}$. To allow microbial acclimatization to the salinity stress, the influent salt salinity was maintained at 5,10 , and $15 \mathrm{~g} / \mathrm{L} \mathrm{NaCl}$ for two weeks. Error bars represent the standard deviation of two measurements (once per week) at each salinity condition. 


\section{RESEARCH HIGHLIGHTS}

- High salinity reduced biogas production and COD removal in AnMBR

- Removal of hydrophilic TrOCs by AnMBR decreased as bioreactor salinity increased

○ Removal of hydrophobic TrOCs was constantly high regardless of salinity build-up

- Elevated bioreactor salinity slightly affected TrOC residuals in the sludge 